\title{
KONSEP DESAIN KENDARAAN LISTRIK RODA TIGA RAMAH LINGKUNGAN
}

\section{DESIGN CONCEPT THREE-WHEELED ELECTRICAL VEHICLES THAT ARE ENVIRONMENTALLY FRIENDLY}

\author{
Febryan Maulana \\ Pusat Teknologi Industri Permesinan, TIRBR - BPPT, \\ Gd. Teknologi 2 Puspiptek, Serpong \\ e-mail : febryan.maulana@bppt.go.id
}

\begin{abstract}
Abstrak
Dalam penelitian ini dirancang sebuah kendaraan listrik roda tiga dengan menggunakan metode VDI (Verein Duetscher Ingeniure). Perancangan kendaraan listrik ini terfokus pada desain kontruksi rangka dan perhitungan kebutuhan motor listrik yang sesuai sebagai elemen utama kendaraan listrik. Dalam perancangan kendaraan listrik roda tiga terdapat 3 varian dan berdasarkan nilai evaluasi varian yang paling tinggi adalah varian 2 dengan nilai 0,05 . Kendaraan roda tiga mempunyai dimensi panjang $2500 \mathrm{~mm}$, lebar $1250 \mathrm{~mm}$, tinggi $1400 \mathrm{~mm}$ dengan tingkat kestabilan 46\%.

Setelah dilakukan analisa dan pengujian terhadap kontruksi rangka yang menggunakan bahan S45C, maka dapat diketahui bahwa kontruksi rangka ini mampu menahan beban sebesar $250 \mathrm{~kg}$. Dan dengan spesifikasi motor listrik 5 $\mathrm{Kw}$ yang dibutuhkan pun tersedia di pasar, sehingga memungkinkan kendaraan listrik roda tiga ini untuk dikembangkan lebih lanjut.
\end{abstract}

Kata kunci : transportasi, kendaraan listrik, kendaraan listrik roda tiga, metode VDI

\begin{abstract}
In this study will be designed a three-wheeled electric vehicle using the VDI (Verein Duetscher Ingeniure). The design of electric vehicles is focused on the design and calculation of required construction frame corresponding electric motor as the main element of the electric vehicle. In the design of three-wheeled electric vehicles, there are 3 variants and variants based on the value of the highest evaluation is a variant 2 with a value of 0.05 . Three-wheeled vehicle has dimensions of length $2500 \mathrm{~mm}$, width $1250 \mathrm{~mm}$, height $1400 \mathrm{~mm}$ with a $46 \%$ degree of stability.

After analysis and testing of construction materials using S45C frame, it can be seen that the frame construction can support the weight of $250 \mathrm{~kg}$. And with a $5 \mathrm{Kw}$ electric motor specifications required is available in the market, thus allowing the three-wheeled electric vehicles to be developed further.
\end{abstract}

Keywords : Transportation, Electric Vehicle, Three-Wheeled Electric Vehicle, VDI

Diterima (received) : 20 April 2016, Direvisi (reviewed) : 20 Juni 2016, Disetujui (accepted) : 15 Juli 2015

\section{PENDAHULUAN}

Transportasi merupakan sarana yang sangat penting dalam menunjang keberhasilan pembangunan terutama dalam mendukung kegiatan perekonomian masyarakat untuk memenuhi kebutuhan barang dan jasa sehari-hari, serta meningkatkan kualitas kehidupan sosial ekonomi.
Pertumbuhan populasi kendaraan yang tak terkendali menjadi penyebab meningkatnya permintaan energi oleh konsumen. Di satu sisi bahwa ekonomi Indonesia semakin baik tapi di sisi lain menimbulkan permasalahan baru yaitu kemacetan, dan polusi udara yang dihasilkan emisi gas buang kendaraan.

$$
\text { Dari data Badan Pengelolaan }
$$

Lingkungan Hidup (BPLDH) dari berbagai 
sektor yang potensial dalam mencemari udara, pada umumnya sektor transportasi memegang peran yang sangat besar dibandingkan dengan sektor lainnya. Di kotakota besar, kontribusi gas buang kendaraan bermotor sebagai sumber polusi udara mencapai $60-70 \%$. Sedangkan kontribusi gas buang dari cerobong asap industri hanya berkisar $10-15 \%$, sisanya berasal dari sumber pembakaran lain, misalnya dari rumah tangga, pembakaran sampah, kebakaran hutan, dan lain-lain. [12]

Electric vehicle atau Kendaraan Listrik adalah solusi dari masalah cadangan minyak bumi yang kian menipis serta masalah polusi yang tiap tahunnya meningkat akibat emisi gas buang yang dihasilkan kendaraan berbahan bakar minyak. Di negara-negara maju kendaraan ini sudah sangat lazim digunakan, bahkan sudah dimasyarakatkan.

Dari pemaparan diatas, maka penulis mencoba untuk merancang sebuah konsep kendaraan listrik roda tiga berpenumpang dua orang dengan menggunakan metode VDI (Verein Duetscher Ingeniure) dengan fokus perancangan terhadap desain bentuk dan dimensi kendaraan yang ramping dengan menggunakan motor listrik yang sesuai agar kendaraan listrik ini dapat bekerja secara optimal, efisien dan ramah lingkungan.

\section{LANDASAN TEORI Metode VDI 2221}

Metode VDI (Verein Deutscher Ingeniure/ Persatuan Insinyur Jerman) yaitu pendekatan sistematik terhadap desain untuk sistem teknik dan produk teknik. Metode VDI 2221 yang disusun oleh Gerhard Pahl dan Wolfgang Beitz dalam buku "Engineering Design" ini dibagi beberapa tahapan:

\section{Penjabaran tugas (Clarifying the Task) \\ Tujuan dari tahap ini untuk mengumpulkan Informasi dan menguraikanya sejelas mungkin dalam bentuk daftar spesifikasi serta} mengidentifikasikan kendala-kendala yang dihadapi untuk mencapai solusi optimal. Yang harus diperhatikan dalam menyiapkan daftar spesifikasi membedakan sebuah persyaratan apakah sebagai keharusan (demand) atau keinginan (wishes).

Demand adalah segala persyaratan yang harus dipenuhi dalam segala kondisi, dengan kata lain apabila tidak dipenuhi, maka solusi yang tercapai tidak dapat diterima. Dan segala persyaratan minimum harus di formulasikan dengan jelas. Wishes adalah segala persyaratan yang diinginkan bisa dimasuki melalui pertimbangan

\section{Perancangan konsep (Conceptual Design)}

Adapun yang dibahas dalam perancangan konsep ini meliputi abstraksi, pembuatan struktur fungsi, pencarian dan kombinasi prinsip solusi, pemilihan kombinasi yang sesuai, pembuatan varian konsep, serta evaluasi. Perancangan konsep mencakup tahapan- tahapan seperti ditujnukan pada gambar.

\section{Perancangan wujud (Embodimen Design)}

Perancangan wujud dimulai dengan konsep produk teknik, kemudian dengan menggunakan kriteria teknik dan ekonomi, perancangan dikembangkan dengan menguraikan struktur fungsi kedalam struktur modul untuk memperoleh elemen-elemen pembangun struktur fungsi yang memungkinkan dapat dimulainya perancangan yang lebih rinci.

Langkah ini dapat menjadi umpan balik pada langkah sintesis untuk pencarian alternatif solusi yang lebih baik. Analisa diikuti evaluasi dimana dapat timbul kemungkinan perlu dibuatnya model atau protipe untuk dapat mengukur kinerja, kualitas, kemudahan dan beberapa kriteria lain dari hasil perancangan.

4. Perancangan detail (Detail Design)

Tahap ini merupakan akhir metode perancangan sistematis yang berupa presentasi hasil. Pada langkah kerja ini, dilakukan pekerjaan-pekerjaan, merinci gambar akhir, termasuk gambar terperinci mengenai tiap-tiap bagian/ elemen dari produk. Merinci setiap data perakitan dan data-data lain yang berhubungan dengan persiapan produksi/pembuatan. Pada akhir tahap ini dievaluasi kembali untuk melihat apakah produk mesin atau sistem teknik tersebut benar-benar sudah memenuhi spesifikasi dan semua gambar-gambar dokumen produk lainnya telah selesai dan lengkap.

\section{Dimensi Kendaraan}

Kendaraan yang akan di Indonesia harus memenuhi kriteria yang tercantum pada Peraturan Pemerintah Republik Indonesia Nomor 55 Tahun 2012. Berdasarkan Peraturan Pemerintah Republik Indonesia Nomor 55 Tahun 2012 tentang kendaraan:

Paragraf 4 (Ukuran) Pasal 54 Ayat:

1. Ukuran Kendaraan Bermotor selain Sepeda Motor harus memenuhi persyaratan:

a. Panjang tidak melebihi 12.000 (dua belas ribu) milimeter untuk kendaran bermotor tanpa kereta gandengan atau kereta tempelan selain mobil bus

b. Lebar tidak melebihi 2.500 (dua ribu lima ratus) milimeter;

c. Tinggi tidak melebihi 4.200 (empat ribu dua ratus) milimeter dan tidak lebih dari 1,7 (satu koma tujuh) kali lebar Kendaraan;

d. Sudut pergi Kendaraan paling sedikit $8^{\circ}$ 
(delapan derajat) diukur dari atas permukaan bidang atau jalan yang datar;

2. Panjang bagian Kendaraan yang menjulur ke belakang dari sumbu paling belakang maksimum 62,50\% (enam puluh dua koma lima nol persen) dari jarak sumbunya, sedangkan yang menjulur ke depan dari sumbu paling depan maksimum 47,50\% (empat puluh tujuh koma lima nol persen) dari jarak sumbunya.

3. Dalam hal Kendaraan Bermotor memiliki tinggi keseluruhan lebih dari 3.500 (tiga ribu lima ratus) milimeter, wajib dilengkapi dengan tanda.

4. Tanda sebagaimana dimaksud pada ayat (3) berupa tulisan yang mudah dilihat oleh pengemudi di dalam ruang pengemudi.

Pasal 116 ayat 1

Becak sebagaimana dimaksud dalam Pasal 114 ayat (1) huruf b harus memiliki ukuran:

a. lebar maksimum 1.500 (seribu lima ratus) milimeter;

b. tinggi maksimum 1.800 (seribu delapan ratus) milimeter; dan

c. panjang maksimum 2.800 (dua ribu delapan ratus) milimeter.

\section{Komponen Utama Pada kendaraan Listrik} Secara fungsional komponen utama dari kendaraan dapat dikelompokan menjadi jenis yaitu: [5]:

1. Mesin (Engine)

Komponen mesin atau komponen pembangkit tenaga adalah komponen yang fungsi utamanya menghasilkan dan merubah tenaga dari tenaga listrik menjadi tenaga mekanis putar.

\section{Rangka (Chasis)}

Komponen rangka chasis kendaraan adalah komponen kendaraan yang fungsi utamanya adalah sebagai rangka penguat konstruksi bodi kendaraan agar mampu menahan beban kendaraan dan beban impak saat terjadi tabrakan sehingga dapat melindungi penumpang. Untuk kendaraan yang dirancang untuk berjalan dimedan yang berat sehingga beban operasi yang diterima oleh rangka dan bodi sangat besar, maka rangka chasis dibuat kokoh dan terpisah dari bodi Bodi.

3. Bodi

Komponen bodi kendaraan adalah komponen yang berfungsi melindungi dan mengamankan penumpang dari gangguan luar dan melindungi penumpang dari beban impak yang terjadi akibat kecelakaan atau tabrakan. Disamping itu bagian alam bodi berfungsi juga untuk memberikan kenyamanan penumpang dan pengaman pada saat tabrakan.

4. Penyimpan Tenaga / Baterai

Baterai adalah alat listrik-kimiawi yang berfungsi menyimpan energi dan mengeluarkan tenaganya dalam bentuk listrik. Biasanya mobil listrik menggunakan jenis baterai lithium yang menghasilkan daya energi yang tinggi dan aman dalam penggunaannya.

5. Pengarah Gerak / Kemudi

Komponen pengarah gerak atau kemudi adalah berfungsi untuk mengarahkan gerakan kendaraan sesuai dengan keinginan pengemudi. Kalau ditinjau dari tenaga penggerak roda untuk berbelok sampai saat ini sistem kemudi dapat digolongkan menjadi 2 yaitu: sistem manual dan sistem "power steering". Sistem kemudi harus dirancang besaran sudut belok roda kiri dan kanan sedemikian rupa agar pada saat kendaraan berbelok kendaraan memiliki satu titik putar sementara (instateneous centre) agar keausan roda bisa berimbang. Hal ini berarti belokan roda kiri dan kanan besarnya tidak boleh sama, pada saat berbelok roda sebelah dalam harus berbelok lebih besar dibandingkan belokan roda sebelah luar.

6. Rem

Komponen yang dapat mengurangi kecepatan dan untuk menghentikan kendaraan adalah sistem rem kendaraan. Ditinjau dari sumber gaya yang digunakan untuk menimbulkan gaya rem pada roda, sistem rem dapat dibedakan menjadi 2 macam. Pertama adalah sistem rem manual dimana gaya rem yang terjadi pada setiap roda kendaraan seluruhnya bersumber pada gaya injakan pedal rem yang dilakukan oleh pengemudi. Model yang kedua adalah sistem "power brake" yaitu sistem rem dimana gaya rem pada roda bersumber pada gaya dari sitem hidraulik, gaya dari sistem pneumatik, atau gaya dari sistem elektrik.

\section{Analisis Stabilitas}

\section{Prilaku Ackerman}

Perilaku ackerman merupakan perilaku belok kendaraan yang ideal, kendaraan akan berbelok mengikuti gerakan ackerman dimana tidak terjadi sudut slip pada setiap roda. Pada kecepatan rendah roda tidak memerlukan gaya lateral sehingga pada saat berbelok belum menimbulkan sudut slip. Pusat belok dari kcndaraan merupakan perpotongan garis yang berhimpit pada dengan poros belakang dengan garis tegak lurus terhadap sudut belok depan. [5] 


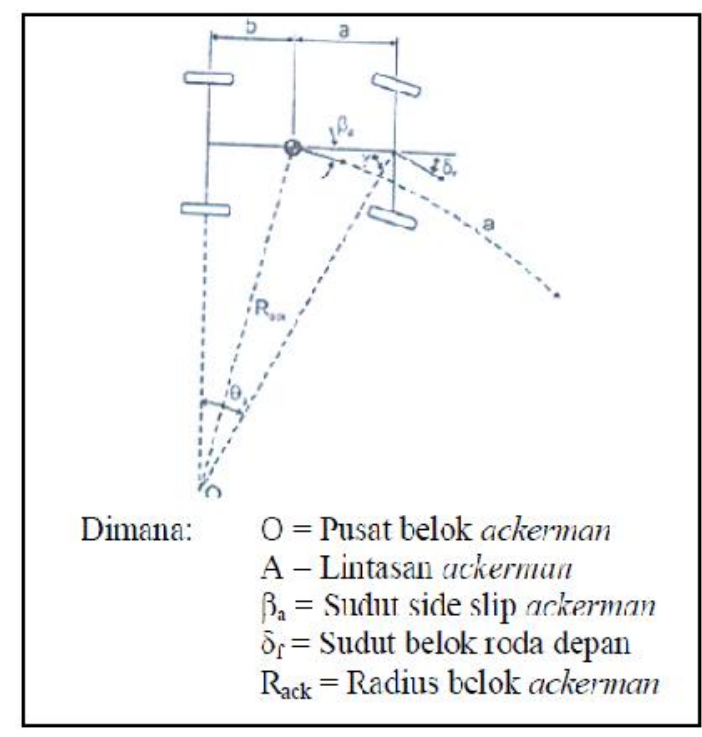

Gambar 1.

Prilaku Ackerman

\section{Safety Factor}

Safety factor adalah salah satu parameter kinerja kendaraan yang berkaitan dengan stabilitas kendaraan. Nilai dari parameter ini akan merekomendasi, apakah kendaraan layak diuji lapangan.

Cara mencari safety factor (SF) yaitu:

$S F=\left(\frac{67 T}{H}\right)-100$ atau

$S F=100\left(\frac{T-1.5 \mathrm{H}}{1.5 \mathrm{H}}\right)$

Dimana :

$\mathrm{SF}=$ Safety Factor ( \% )

$\mathrm{H}=$ Ketinggian Centre of Grafity dalam (m)

$\mathrm{T}=$ Wheel Track $(\mathrm{m})$

Tabel 1.

Stabilitas

Stabilitas
STABILITY TABLE

\section{SAFETY FACTOR, SF, Percent}

Less than or equal to zerro $(<\mathrm{or}=0)$

0 to 21

22 to 33

34 to 50

51 to 75

Greater than $75(>75)$

\section{RATING}

Failst Test!

Extraordinary unsafe

Unsafe

Marginal

Acceptable

Very safe

Extremly desirable but not attainabble*
- Secara teoritis apabila nilai SF berada pada zona merah ( $\mathrm{SF} \leq 0)$ ) artinya kendaraan sangat tidak aman dan tidak layak untuk dilakukan test lapangan karena akan terjadi oversteering sehngga kendaraan akan terbalik.

- Nilai SF berada pada zona orange ( $0<\mathrm{SF} \leq$ 0,21 ) artinya mobil tidak aman apabila dilakukan uji lapangan karena stabilitasnya sangat rendah dimana gaya cengkram mobil terhadap jalan sangat rendah.

- Sedangkan untuk nilai SF yang berada pada zona kuning $(0,21<\mathrm{SF} \leq 0,33)$ artinya kinerja kendaraan sulit untuk diprediksi pada saat uji lapangan, sebaiknya kendaraan tidak perlu dilakukan uji lapangan.

- Untuk nilai SF berada pada zona hijau mudah $(0,33<\mathrm{SF} \leq 0,51)$ artinya kinerja stabilitas kendaraan bisa diterima, namun dengan mempertimbangkan uji lapangan yang bersifat dinamik maka gaya sentrifugal yang bekerja pada kondisi kendaraan berbelok akan memberikan kecendrungan kendaraan akan oversteering dan kehilangan kontrol.

Untuk nilai SF berada pada zona hijau tua artinya kendaraan dalam keadaan sangat aman dalam kondisi statis sehingga dapat dilakukan uji lapangan. Berdasarkan analisis secara teoritis maka kendaraan yang nilai SF mendekat 0,75 adalah kendaraan yang paling layak. Sedang untuk nilai SF lebih tinggi dari pada 0,75 biasa sulit diwujudkan karena kendaraan akan memiliki wheel track ( $T$ besar) yang besar dan pendek ( $\mathrm{H}$ kecil).

\section{Mencari Kebutuhan Tenaga Listrik}

Gaya traksi maksimum yang dapat ditahan oleh kontak ban dengan jalan dapat ditentukan dari koefisien adhesi jalan dan parameter kendaraan. Untuk kondisi yang sudah disederhanakan ini maka gaya dorong maksimum yang dapat terjadi pada roda penggerak roda depan atau roda belakang adalah sebagai berikut :

Pada penggerak roda depan

$\mathrm{F}_{\text {maks }}=\mu . \mathrm{Wf}$

$=\mu \cdot\left(\mathrm{W} \frac{\mathrm{I}_{2}}{\mathrm{~L}}-\frac{\mathrm{H}}{\mathrm{L}}\left(\mathrm{F}_{\text {maks }}-\mathrm{Rr}\right)\right)$

Atau

$\frac{F_{\text {nuks }}=\mu \cdot W \cdot\left(I_{z}-f r \cdot H\right)}{L-\mu \cdot H}$

Pada penggerak roda belakang

$F_{\text {maks }}=\mu . W f$

$=\mu \cdot\left(W \cdot \frac{I_{2}}{L}-\frac{H}{L}\left(F_{\text {maks }}-R r\right)\right)$

Atau

$\frac{F_{\text {maks }}=\mu \cdot W \cdot\left(I_{1}+f r \cdot H\right)}{L+\mu \cdot H}$

Jadi secara sederhana dapat dikatakan bahwa gaya dorong maksimum yang dihasilkan pada kendaraan dengan penggerak roda depan 
atau roda belakang adalah tergantung pada : posisi titik berat, tinggi titik berat, koefisien hambatan rolling, koefisien gesek ban dan jalan, dan berat kendaraan itu sendiri. Jika Ffmax > Frmax maka sebaiknya kendaraan tersebut memakai roda depan sebagai roda penggerak dan sebaliknya.

Untuk mencarari torsi pada kendaraan yaitu:

$\frac{F t=i t \cdot i g \cdot M e \cdot \eta t}{r}$

dimana:

$\mathrm{Ft}=\mathrm{Ff}+\mathrm{Fr}=$ gaya dorong pada roda penggerak depan dan belakang. (Newton)

$\mathrm{Ft}=\mathrm{Ff}=$ gaya dorong untuk kendaraan dengan penggerak roda depan. (Newton)

$\mathrm{Ft}=\mathrm{Fr}=$ gaya dorong untuk kendaraan dengan penggerak roda belakang (Newton)

$\mathrm{Me}=$ Torsi keluaran dari mesin $(\mathrm{N} \mathrm{m})$

$\mathrm{R}=$ jari-jari roda $(\mathrm{m})$

$\eta \mathrm{t}=$ efisiensi transmisi

0,88-0,92(untuk meson yang letaknya memanjang, poros penggerak belakang)

0,91 - 0,95 (untuk mesin yang letaknya melintang

it = perbandingan gigi transmisi .

ig = perbandingan transmisi pada gardan .

Limit percepatan maksimum yang dapat dicapai dalam kondisi roda masih rolling yaitu:

$F_{\text {maks }}=m \cdot a_{\text {maks }}$

\section{Daya mesin yang dibutuhkan}

$P($ watt $)=$ T. $\omega$

Dimana :

$\mathrm{T}=$ Torsi $(\mathrm{Nm})$

$\omega=$ yaitu kecepatan sudut pada keadan maksimal ( $\mathrm{rad} / \mathrm{s})$

\section{Aerodinamis}

Pada dasarnya proses perancangan bentuk bodi kendaraan dapat dibagi dalam 5 tahap yaitu basic body, basic shape, basic model, styling model dan tahap akhir yaitu production car seperti pada gambar II-17. Secara umum koefisien hambat aerodinamis dari beberapa jenis kendaraan ditunjukan pada Gambar 2. [5]

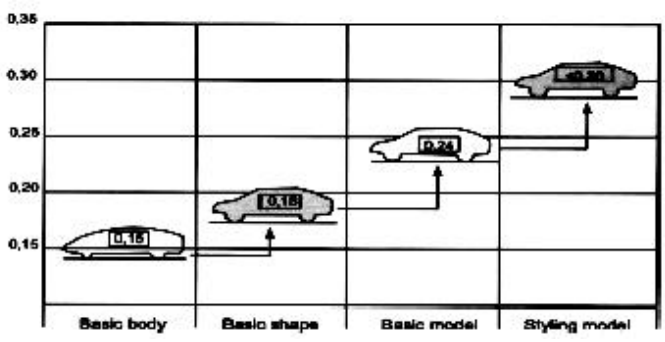

Gambar 2

Tahapan Perencanaan Bodi Kendaraan

Gaya hambat aerodinamik adalah gaya yang bekerja dalam arah horisontal (paralel terhadap aliran) dan berlawanan arah dengan arah gerak maju kendaraan.

$F d=\frac{1}{2} x \rho x C d x A x V^{2}$

Dimana :

- Fd = Gaya dorong (N)

- $\rho$ = Masa jenis Fluida $(\mathrm{Kg} / \mathrm{m3})$

- Cd = Koefisien drag

- A = Luas Frontal kendaraan (m2)

- $\mathrm{v}=$ Kecepatan fluida $(\mathrm{m} / \mathrm{s})$

\section{PERANCANGAN KONSEP}

\section{Penjabaran Tugas (Clarifying Design)}

Dalam tahap ini penulis berusaha mengumpulkan informasi dari berbagai sumber salah satunya dengan membagikan kuesioner kepada 20 responden. Hasil dari responden kemudian dihitung untuk kemudian menguraikannya sejelas mungkin dalam daftar kebutuhan (requirement list), serta mengidentifikasi kendala-kendala yang dihadapi untuk mencapai solusi optimal. Untuk mempermudah penyusunan kebutuhan maka penulis membuat sebuah checklist (daftar periksa).

\section{Perancangan Konsep (Conceptual Design)}

Dari hasil analisis daftar kebutuhan diatas dihasilkan langkah-langkah abstraksi dalam penentuan masalah utama pada perancangan kendaraan listrik, yaitu: Mengabaikan keinginan pribadi atau kehendak (wishes), yang tidak berpengaruh langsung pada fungsi dan kendala-kendala yang penting pada perancangan konsep kendaraan listrik berpenumpang roda tiga. 


\begin{tabular}{|c|c|}
\hline Teknik Mesilm & Daflar Speriflkend \\
\hline Dentied or Wides & Persyaration \\
\hline D & 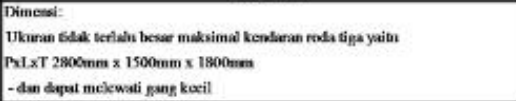 \\
\hline & Rangkix \\
\hline D & Masterial yang digunakan nimgan dan kuat \\
\hline D & Thdak mudah barat \\
\hline$w$ & Thdie oppat noak dum than lana \\
\hline & Sember Energi- \\
\hline D & 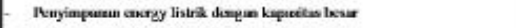 \\
\hline D & 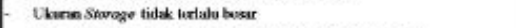 \\
\hline w & 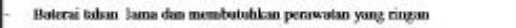 \\
\hline \multirow[t]{2}{*}{$w$} & 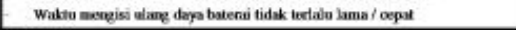 \\
\hline & Pengerick \\
\hline D & Kceasumsi daya rentah \\
\hline D & Mespanyai kecepatis malsimal $60.80 \mathrm{~km}$ jam \\
\hline w & 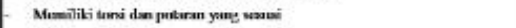 \\
\hline \multirow[t]{2}{*}{ w } & 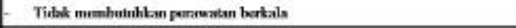 \\
\hline & Operasional: \\
\hline \multirow{2}{*}{$\begin{array}{l}\text { D } \\
\text { w }\end{array}$} & - Mudah dgunakan siapa saja pria dan wanita \\
\hline & - Nyaman sian dgmakan \\
\hline \multirow[b]{5}{*}{$w$} & Kescelamiatur: \\
\hline & - Ada wety bett (Sidnik Kesclamean) \\
\hline & - Adu Air Baq (kantung Uderas) \\
\hline & 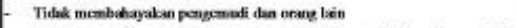 \\
\hline & 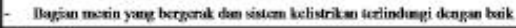 \\
\hline \multirow{4}{*}{$\begin{array}{l}D \\
\text { D } \\
w\end{array}$} & Prowwaliax \\
\hline & 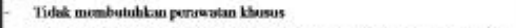 \\
\hline & 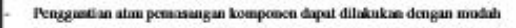 \\
\hline & 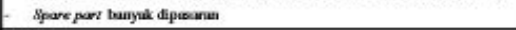 \\
\hline \multirow{4}{*}{$\begin{array}{l}\text { D } \\
\text { D } \\
w\end{array}$} & Spare Phat \\
\hline & 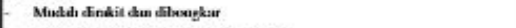 \\
\hline & 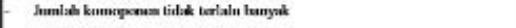 \\
\hline & Rarnya dipresene \\
\hline \multirow[b]{5}{*}{$\mathrm{w}$} & Fitur Tambehine \\
\hline & Mewailib tempes pesyimpanea barang \\
\hline & Mendikiki aliam kermanan \\
\hline & - Mesaliki $A C$ \\
\hline & I. Ada tistem ielio \\
\hline
\end{tabular}

Gambar 3.

Daftar Kebutuhan

Setelah masalah utama diketahui, kemudian dibuat struktur fungsi secara keseluruhan berdasarkan aliran energi, material dan sinyal dengan menggunakan diagram blok yang menunjukan hubungan antara input dan output. Struktur fungsi dibuat setelah ditentukan tugas dari bagian yang dirancang secara keseluruhan yang menjalankan tugas secara terperinci. Untuk kendaraan listrik struktur fungsi secara keseluruhan dijelaskan oleh gambar II-2. Fungsi kendaraan yaitu sebagai alat untuk berpindah yang menggunakan energi listrik sebagai tenaga, sehingga kendaraan berpindah karena adanya energi gerak. Kendaran bergerak karena sinyal yang diberikan oleh pengemudi.

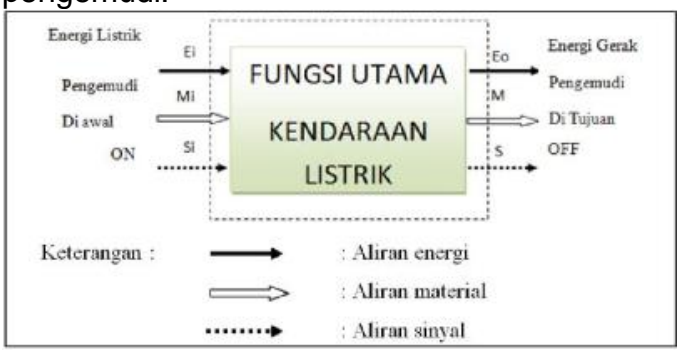

Gambar 4

Struktur Fungsi Keseluruhan

Setelah dibuat struktur fungsi keseluruhan dan sub fungsinya maka selanjutnya dicari prinsip- prinsip solusi untuk memenuhi sub fungsi tersebut.

Metode yang akan digunakan dalam mencari prinsip solusi adalah metode kombinasi, yaitu metode yang mengkombinasikan semua solusi yang ada dalam bentuk matriks. Kemudian dilakukan pemilihan kombinasi dari sub fungsi dan prinsip solusi sehingga terbentuk varianvarian yang paling menunjang.

Prinsip solusi diusahakan sebanyak mungkin, tetapi prinsip-prinsip tersebut perlu dianalisis kembali sehingga prinsip solusi yang kurang bermanfaat dapat dihilangkan atau diabaikan dengan tujuan agar dalam tahap perencanaan konsep selanjutnya tidak terlalu banyak dievaluasi.

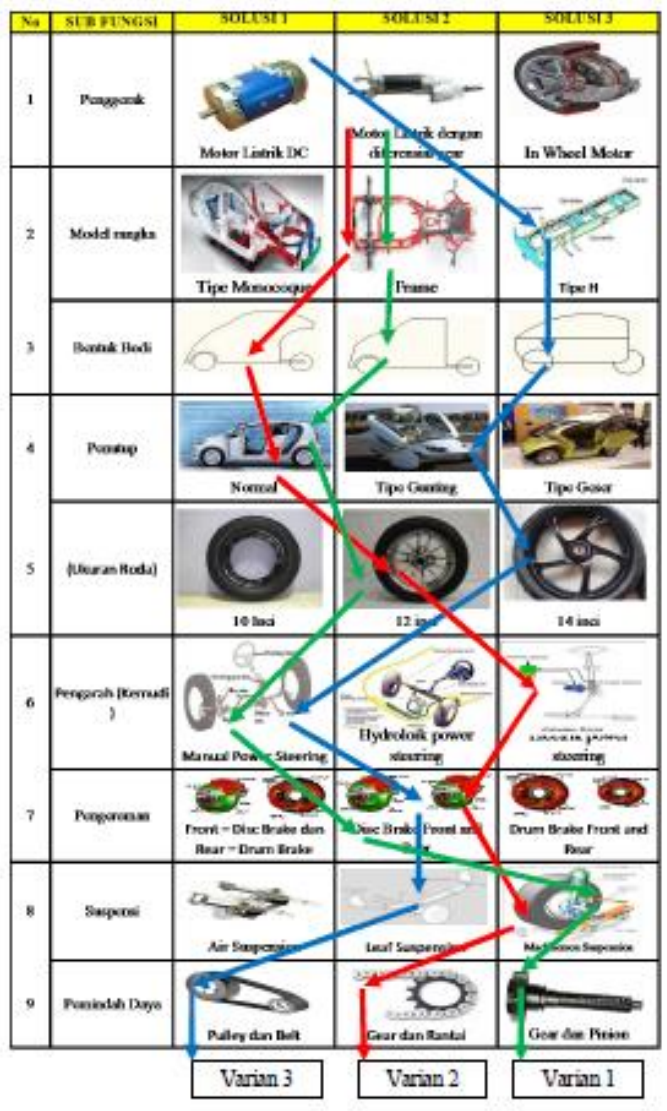

Gambar 5.

Pemilihan kombinasi prinsip solusi

Dari hasil kombinasi prinsip solusi pada tabel II-3 diatas maka dihasilkan kombinasi antara lain:

Varian 1: 1-2, 2-2, 3-1, 4-1, 5-2, 6-3, 7-2, 8-3, 9-2

Varian 2 : 1-2, 2-2, 3-2, 4-1, 5-2, 6-1, 7-2, 8-3, 9-3 Varian 3 : 1-1, 2-3, 3-3, 4-2, 5-3, 6-1, 7-2, 8-2, 9-1

Dari nilai dan criteria pembobotan evaluasi diatas maka pemberian nilai evaluasi dari 3 varian di atas dapat dilihat pada gambar di bawah : 


\begin{tabular}{|c|c|c|c|}
\hline No & Kritera Evaluasi & $B$ & Parame:er \\
\hline $\begin{array}{l}1 \\
2\end{array}$ & $\begin{array}{l}\text { Kehandalan Mesin } \\
\text { Tarrikilll }\end{array}$ & $\begin{array}{l}0.0412 \\
0.0391\end{array}$ & $\begin{array}{l}\text { Waktu } \\
\text { Dayad }\end{array}$ \\
\hline 3 & Kotrsumsi Energi & 0.0442 & Daya \\
\hline 4 & Kestabilan (tidak melayang) & 0.0425 & pengoperasian \\
\hline 5 & Keawetan Mesin & 00612 & Hanga \\
\hline 6 & Keawetan Baterai & 0.0612 & Harga \\
\hline 7 & Kcawctan Komponca Lainnya & 0.0576 & Harga \\
\hline 8 & Pendingin Ruangan ( AC) & 0.0375 & Kenyamanan \\
\hline $\mathbf{9}$ & Auklo & 0.036 & Kenvairsanan \\
\hline 10 & Tempat Penyimpanain Barang & 0.039 & Barang \\
\hline 11 & Power Window & 0.0375 & Kenyamanan \\
\hline 12 & Central Lock & 0.04 & Keamanan \\
\hline 13 & Alamm & 0.0416 & Keamanan \\
\hline 14 & Air Bag (Kantung udara) & 0.04 & Kearincilalı \\
\hline 15 & Sistem rezm ABS & 0.0384 & Kearnianan \\
\hline 16 & Lampu Depan dan Belakang & 0.0416 & Keindahan \\
\hline 17 & Panel Instrument: & 0.0432 & Keindt:han \\
\hline 18 & Desain Velg & 0.0352 & Keindahan \\
\hline 15 & Interior & 0.04 & Keindzhan \\
\hline 20 & Geransi Pembclian Kenderaan & 0.0486 & Harga \\
\hline 21 & Ketersedian Spare Part & 0.045 & Wesklu \\
\hline 22 & Ketersedian Bengkel & 0.045 & waktu \\
\hline 73 & Merjnal ( Harga Jinal Kermhali) & Do4i2) & Hanga \\
\hline & TOTAL & $\mathbf{I}$ & \\
\hline
\end{tabular}

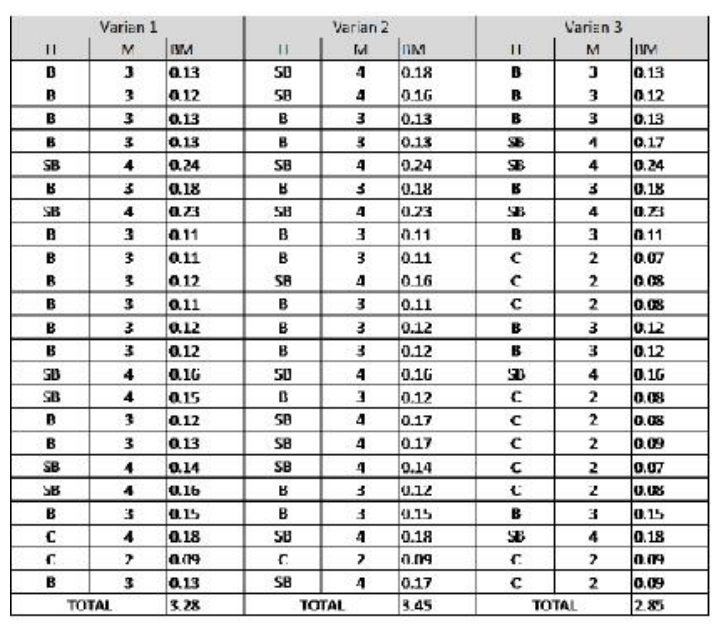

Gambar 6.

Pemberian bobot kriteria varian

Menentukan nilai keseluruhan varian konsep (Determining Overall Weighing Value/OWV) Untuk menentukan rating tiap varian diatas maka digunakan rumussebagai berikut:

$W R J=\frac{O W V J}{V_{\max } \Sigma_{l=1}^{n} W^{i}}$

Varian $1 \mathrm{WRJ}=3,283 \times 23=0.047$

Varian $2 \mathrm{WRJ}=3,453 \times 23=0.05$

Varian $3 \mathrm{WRJ}=2,853 \times 23=0.041$

Setelah rating dari ketiga varian diketahui maka untuk perencanaan selanjutnya dipilih varian ke 2 karena memeiliki rating paling tinggi.

\section{PERANCANGAN WUJUD}

Perancangan Rangka

Analisa Rangka

Dalam menganalisa sebuah rangka maka yang dibutuhkan salah satunya yaitu beban yang diterima oleh rangka. Pada perhitungan rangka kendaraan listrik roda tiga ini beban ststis utamanya yaitu:
F1 : $140 \mathrm{~kg}$ ( 2 orang manusia masing-masing $70 \mathrm{~kg})$

F2 : $110 \mathrm{~kg}$ terdiri dari : - Baterai $90 \mathrm{~kg}$ - Motor Listrik $11 \mathrm{~kg}$

F3 : $80 \mathrm{~kg}$ terdiri dari:

- Rangka gabungan $41 \mathrm{~kg}$

- Bodi (asumsikan) $39 \mathrm{~kg}$

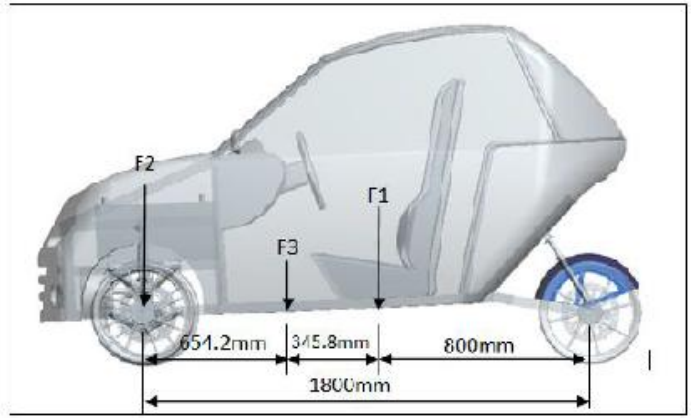

Gambar 7.

Kendaraan Dari Pandangan Samping

Beban yang ditumpu pada roda belakang yaitu:

- $\Sigma M F A=0$

$-F 3 \times 80+F 1 \times 140-F B \times 1800-0$

$=30.654,2+140 \times 1000-F B \times 1800=0$

$=52336+140000=1800 F B$

$F B=1927361800=106,85 \mathrm{~kg} \approx 107 \mathrm{~kg}$

Beban yang ditumpu pada kedua roda depan yaitu:

$F A=F 1+F 2+F 3-F B$

$F A=140+110+80-107$

$F A=223 \mathrm{~kg}$

Pada perhitungan diatas diketahui pada roda belakang beban yang harus di tumpu sebesar $107 \mathrm{~kg}$ sedangkan pada kedua roda depan beban yang harus ditumpu sebesar $223 \mathrm{~kg}$. Setelah diketahui beban yang di tumpu pada roda depan dan roda belakang maka selanjutnya mencari resultan atau titik pusat dari beban distribusi pada rangka gabungan.

$\Sigma M=0$

$F A \cdot L=M_{\text {tot }} \cdot a$

$a=\frac{F A \cdot L}{M_{\text {tot }}}$

$=223.1800330=1216,36 \mathrm{~mm} \approx 1216 \mathrm{~mm}$

Dari perhitungan tersebut maka diketahui jarak dari titik roda depan (I1) dengan titik pusat masa sebesar $584 \mathrm{~mm}$ dan jarak dari titik pusat masa ke titik roda belakang (I2) yaitu $1216 \mathrm{~mm}$.

\section{Kebutuhan Motor Listrik}

Untuk dapat mengetahui kebutuhan minimal tenaga motor listrik maka pertama-tama dihitung gaya dorong kendaraan maksimum oleh tumpuan ban dengan jalan. Untuk menghitungnnya dapat ditentukan dari koefisien adhesi jalan dan parameter berat kendaraan. 
TABEL 2

KOEFISIEN ADHESI JALAN

\begin{tabular}{lcc}
\hline \multicolumn{1}{c}{ Surface } & $\begin{array}{c}\text { Peak } \\
\text { Value }\end{array}$ & $\begin{array}{c}\text { Sliding } \\
\text { Value }\end{array}$ \\
\hline Asphalt and concrete dry & $0.8-0.9$ & 0.75 \\
Asphalt (wet) & $0.5-0.7$ & $0.45-0.6$ \\
Concentrate (wet) & 0.8 & 0.7 \\
Gravel & 0.6 & 0.55 \\
Earth Road (dry) & 0.68 & 0.65 \\
Earth Road (wet) & 0.55 & $0.4-0.5$ \\
Snow (hard-packed) & 0.2 & 0.15 \\
\multicolumn{1}{c}{ Ice } & 0.1 & 0.07 \\
\hline
\end{tabular}

\section{KOEFISIEN TAHANAN ROLING}

$\mathrm{Me}=53,27 \mathrm{Nm}$

Jika kendaraan dapat berjalan dengan kecepatan $60 \mathrm{~km} / \mathrm{jam}$ dengan diameter roda yaitu $0,45 \mathrm{~m}$ maka kecepatan minimal putaran roda yaitu:

Kec. Maksimun : $60 \mathrm{Km} / \mathrm{jam}=16.67 \mathrm{~m} / \mathrm{s}$.

Putaran roda $: V=\frac{2 \pi n R}{60}$

$n=\frac{V .60}{2 \pi n R}=\frac{16.67 \times 60}{2 \pi 0.225}=707.49 \mathrm{Rpm}$

Kecepatan sudut $=\frac{2 \pi n}{60}$

$=2.3,14 \times 707,4960$

$=74,1 \mathrm{rad} / \mathrm{sec}$

Daya mesin yang dibutuhkan

$$
\begin{aligned}
& (P)=T \cdot \omega \\
& =53,27.74,1 \\
& =3947,63 \text { watt } \sim 4 K W
\end{aligned}
$$

\begin{tabular}{|c|c|c|}
\hline \multirow{3}{*}{$\begin{array}{l}\text { Aspal hotmix dan } \\
\text { beton cor }\end{array}$} & & \\
\hline & Kondisi & ungan susut belok kend \\
\hline & Kondi & a sudut belok roda kendaraan paling $\mathrm{k}$ \\
\hline Jalan paving blok & & $\begin{array}{l}\text { sedangkan sudut belok roda kendaraan } \\
\text { besar yaitu } 36.30 \text {. Kemudian pada }\end{array}$ \\
\hline Jala & & $0.020-0.025$ perancangan ini untuk sudut belok kendaraan \\
\hline Jala & $\begin{array}{l}\text { kering } \\
\text { becek }\end{array}$ & $\begin{array}{l}\text { esar 320. Dari prilaku ackerman atau gerakan } \\
\text { tk ideal dapat dihitung dengan rumus: }\end{array}$ \\
\hline
\end{tabular}

\footnotetext{
Jenis Jalan

$\mathrm{f}$ (nilai rata-ratsistem Kemudi

Jalan berpasir

$0.10-0.30$

Jalan bersalju

$0.07-0.10$

Koefisien adhesi jajan diambil $=0,75$

Tahanan roling diambil $f=0,014$

$F x \operatorname{maxs}=\frac{\mu W\left(I_{\hat{\imath}}+f \cdot H\right)}{L+\mu \cdot H}$

Fx $\max$

$=\frac{0,75.330 .9,81 \cdot(1.216+0.014 \times 0,5)}{1,8+0,75.05}$

$F x \max =\frac{2935,42}{2,1275}=1349,619 \mathrm{~N}$

Kemudian memperhitungkan limit percepatan maksimum yang dapat dicapai dalam kondisi roda masih rolling yaitu:

Fmaks $=$ m.amaks

amaks $=\frac{1349,616}{330}=4 \mathrm{~m} / \mathrm{s} 2$

Setelah gaya traksi dan limit percepatan diketahui maka selanjutnya yaitu menghitung torsi pada roda. Jika diametar roda yang dipakai yaitu $0,45 \mathrm{~m}$ dan menggunakan diferensial gearb box dengan rasio 6:1 maka torsi yang dibutuhkan untuk memutar roda :

$$
\begin{gathered}
\frac{F t=i t \cdot i g \cdot M e \cdot \eta t}{r} \\
1349,616=\frac{6 \cdot M e}{0.225 \cdot 0,95}
\end{gathered}
$$

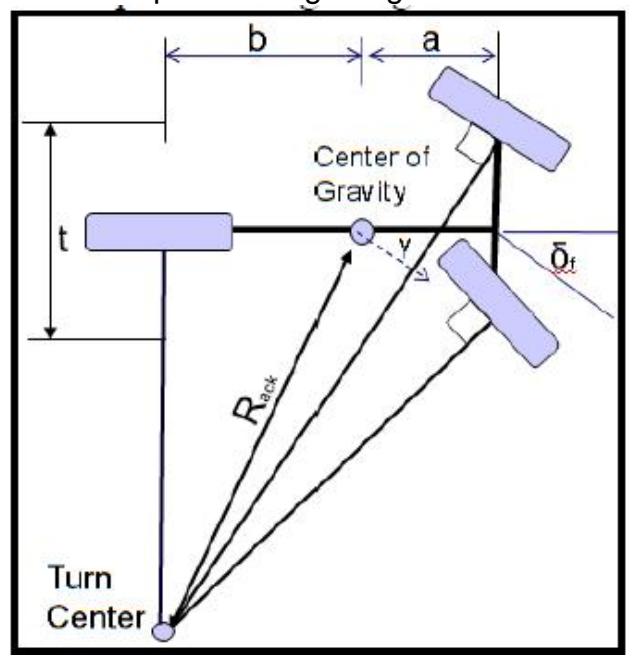

Gambar 9.

Raduis Ackerman

Diketahui:

$a+b=1.8 m, \delta f=32^{0}, y=58^{\circ}, \beta=21.9^{0}$

Rack $=\frac{a+b}{\theta_{a}{ }^{0}} 57,29$

Rack $=\frac{1.8}{32^{0}} 57,29$

Rack $=3.22 \mathrm{~m}$

Dari perhitugan ini diketahui bahwa radius putar ideal yaitu sebesar 3,22 meter.
} 


\section{Bentuk Bodi Aerodinamis}

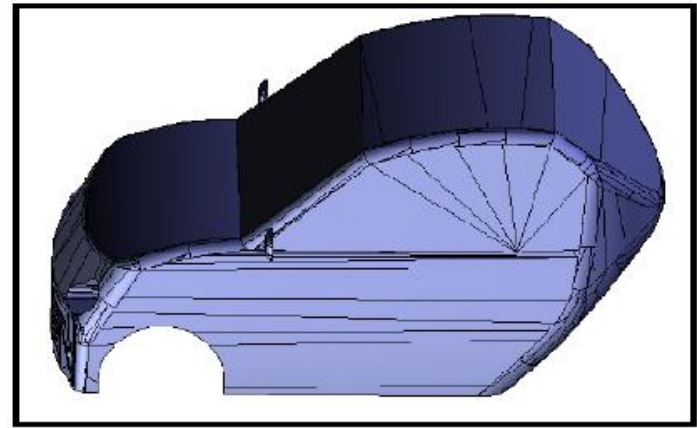

Gambar 8.

Desain Bodi Kendaraan

Untuk mengetahui kendaraan ini termasuk aerodinamis maka harus diketahui gaya hambat kendaraan ( Cd)

$r d=\frac{1}{2} x p x \operatorname{Cdx} A x V^{2}$

Dimana :

- $\mathrm{Fd}=$ Gaya dorong $(\mathrm{N})$

- $\rho$ = Masa jenis Fluida $(\mathrm{Kg} / \mathrm{m} 3)$

- A = Luas Frontal kendaraan (m2)

$-\mathrm{v}=$ Kecepatan fluida $(\mathrm{m} / \mathrm{s})$

Jika diketahui luas frontal $(A)=1,625 . \mathrm{m}$, masa jenis fluida yaitu udara ( $\rho) 1.2 \mathrm{Kg} / \mathrm{m} 3$ pada suhu normal 270 kecepatan angin (v) $60 \mathrm{~km} / \mathrm{jam}$ atau $16,6 \mathrm{~m} / \mathrm{s}$, coefisien drag $(\mathrm{Cd})=0,18$ kendaraan listrik roda tiga yaitu:

$F d=\frac{1}{2} x \rho x C d x A x V^{2}$
$F d=\frac{1}{2} 1,2 \cdot 0 \cdot 18 \cdot 1,625 \cdot(16)^{2}$
$=78,8 \mathrm{~N}$

\section{Safety Faktor}

Untuk dapat mengetahui kestabilan kendaraan sebelum diuji maka nilai dari parameter ini akan merekomendasi, apakah laik diuji lapangan atau tidak. Diketahui wheeltrack $(T)$ sebesar 1,1 meter dan tinggi dari pusat masa $(\mathrm{H})$ sebesar 0,5 meter maka digunakan rumus:

$$
\begin{aligned}
F & =100\left(\frac{T-1.5 \mathrm{H}}{1.5 \mathrm{H}}\right) \mathrm{SF} \\
& =\frac{100(1.1-1.5 \times 0,5)}{1.5 \times 0.5} \mathrm{SF} \\
\mathrm{SF} & =100(0.380 .72)=46 \%
\end{aligned}
$$

Pada tabel stabilitas nilai SF $46 \%$ berada pada zona hijau mudah $(0,33<\mathrm{SF} \leq 0,51)$ artinya kinerja stabilitas kendaraan bisa diterima, namun dengan mempertimbangkan uji lapangan yang bersifat dinamik maka gaya sentrifugal yang bekerja pada kondisi kendaraan berbelok akan memberikan kecendrungan kendaraan akan oversteering dan kehilangan kontrol.

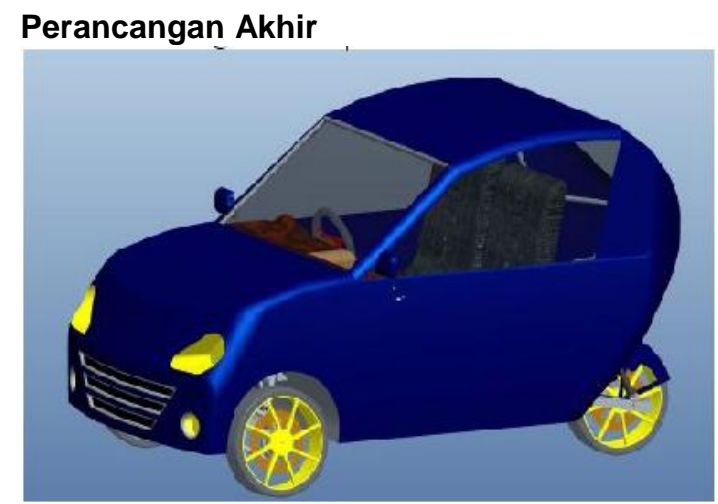

Gambar 10.

Desain Kendaraan Listrik

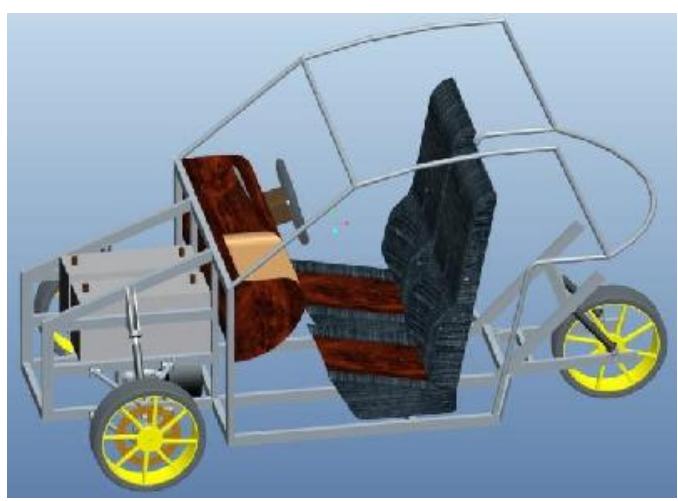

Gambar 11.

Desain Isi Kendaraan Listrik

\section{SIMPULAN}

Perancangan kendaraan listrik roda tiga dengan menggunaan metode VDI 2221 terdapat 3 varian dan berdasarkan nilai evaluasi varian yang paling tinggi adalah varian 2 dengan nilai 0,05 . Kebutuhan daya motor untuk mengerakan kedaraan listrik roda tiga yaitu $4 \mathrm{Kw}$ dan akan menggunakan motor tipe BLDC $5 \mathrm{Kw} 48$ Volt.

Dimensi kendaraan listrik roda tiga yaitu:

\begin{tabular}{llc} 
- & Panjang & $: 2500 \mathrm{~mm}$ \\
- & Lebar & $: 1250 \mathrm{~mm}$ \\
- & Tinggi & $: 1400 \mathrm{~mm}$ \\
- & Jarak sumbu roda ( Wheelbase ) \\
& \multicolumn{3}{c}{$: 1800 \mathrm{~mm}$} \\
- & \multicolumn{2}{c}{ Jarak sumbu roda depan (Wheelltrack) } \\
& \multicolumn{3}{c}{$: 1100 \mathrm{~mm}$} \\
- & Jarak terendah ke tanah $: 200 \mathrm{~mm}$
\end{tabular}

Komponen yang dipakai antara lain

$\begin{array}{lll} & \text { Mesin } & \text { : Motor Listrik Tipe BLDC } \\ & \text { Daya } & : 5 \mathrm{Kw} \\ \text { - } & \text { Baterai } & : \text { Lithium lon } 180 \mathrm{Ah} \\ \text { - } & \text { Gearbox } & : \text { Diferensial Gear dengan } \\ & \text { rasio 6:1 } & \\ \text { - } & \text { Velg } & : 12 \text { Inci } \\ \text { - } & \text { Ban } & : 155 / 70 \mathrm{R} 12\end{array}$




\section{- Suspensi Type : MacPheson \\ - Rem : Dish Brake \\ - Kec. Maksimal : $60 \mathrm{~km} / \mathrm{jam}$ \\ - Beban yang dapat diangkut : $140 \mathrm{~kg}$}

\section{UCAPAN TERIMA KASIH}

Saya ucapkan terima kasih kepada rekan rekan mahasiswa Universitas Pancasila dan rekan rekan PNJ atas bantuannya yang membantu dalam kelancaraan penelitian saya ini.

\section{DAFTAR PUSTAKA}

1. Cross, Nigel., Engineering Design Methods,

John Wiley \& Sons Ltd.,UK, 2000

2. Jajang Palah, Perancangan dan Pembuatan Kendaraan ARJUNA dengan Menggunakan Metode VDI 2221, Skripsi Tugas Akhir Teknik Mesin Universitas
Pancasila, Jakarta, 2010

3. Khurmi,R.S dan Gupta, J. K., A Teks Books of Machine Design. Eurasia Publising house (Ovt) LTD., New Delhi, 1991

4. Maulana Eka, Modul Integrated Project 2, Universitas Pancasila, Jakarta, 2011

5. Nyoman Sutantra \& Bambang Sampurno; "Teknologi Otomotif", Surabaya.2101

6. Pahl, G dan W. Beitz, Engineering Design, The Design Council, London, 1984

7. Ruli Nutranta, "Perancangan Produk", Pusat Pengembangan Bahan Ajar-UMB

8. Sato, Takeshi., Menggambar Mesin, PT Pradnya Paramita, Jakarta, 2003

9. Stone Richard and Jeffrey K. Ball, "Automotive Engineering Fundamentals", SAE International, Warrendale, PA.

10. Thomas D. Gillespie; "Fundamentals of Vehicle Dynamics", Society of Automotive Engineering. Inc. 1994

11. Yahdi Umar, "Pengantar Fisika Teknk", GUNADARMA, 1996 